\title{
Parathyroid Hormone Treatment Increases Fixation of Orthopedic Implants with Gap Healing: A Biomechanical and Histomorphometric Canine Study of Porous Coated Titanium Alloy Implants in Cancellous Bone
}

\author{
Henrik Daugaard • Brian Elmengaard • \\ Troels Andreassen • Joan Bechtold • \\ Anders Lamberg • Kjeld Soballe \\ Received: 17 April 2010/Accepted: 18 November 2010/Published online: 21 January 2011 \\ (C) The Author(s) 2011. This article is published with open access at Springerlink.com
}

\begin{abstract}
Parathyroid hormone (PTH) administered intermittently is a bone-building peptide. In joint replacements, implants are unavoidably surrounded by gaps despite meticulous surgical technique and osseointegration is challenging. We examined the effect of human PTH(1-34) on implant fixation in an experimental gap model. We inserted cylindrical $(10 \times 6 \mathrm{~mm})$ porous coated titanium alloy implants in a concentric 1-mm gap in normal cancellous bone of proximal tibia in 20 canines. Animals were randomized to treatment with $\mathrm{PTH}(1-34)$ $5 \mu \mathrm{g} / \mathrm{kg}$ daily. After 4 weeks, fixation was evaluated by histomorphometry and push-out test. Bone volume was increased significantly in the gap. In the outer gap $(500 \mu \mathrm{m})$, the bone volume fraction median (interquartile range) was $27 \%(20-37 \%)$ for PTH and $10 \%(6-14 \%)$ for control. In the inner gap, the bone volume fraction was $33 \%$ (26-36\%) for PTH and 13\% (11-18\%) for control. At the implant interface, the bone fraction improved with $16 \%$ (11-20\%) for PTH and 10\% (7-12\%) $(P=0.07)$ for control. Mechanical implant fixation was improved for implants exposed to PTH. For PTH, median (interquartile range) shear stiffness was significantly higher (PTH 17.4
\end{abstract}

The authors have stated that they have no conflict of interest.

H. Daugaard $(\square) \cdot$ B. Elmengaard · A. Lamberg $\cdot$ K. Soballe Orthopaedic Department, Aarhus University Hospital, Aarhus, Denmark

e-mail: h.daugaard@dadlnet.dk

T. Andreassen

Department of Anatomy, Aarhus University, Aarhus, Denmark

J. Bechtold

Excelen Center for Bone and Joint Research and Minneapolis

Medical Research Foundation, Minneapolis, MN, USA
[12.7-39.7] $\mathrm{MPa} / \mathrm{mm}$ and control 8.8 [3.3-12.4] $\mathrm{MPa} / \mathrm{mm})$ $(P<0.05)$. Energy absorption was significantly enhanced for PTH (PTH 781 [595-1,198.5] $\mathrm{J} / \mathrm{m}^{2}$ and control 470 [189-596] $\mathrm{J} / \mathrm{m}^{2}$ ). Increased shear strength was observed but was not significant (PTH 3.0 [2.6-4.9] and control 2.0 [0.9-3.0] MPa) $(P=0.08)$. Results show that PTH has a positive effect on implant fixation in regions where gaps exist in the surrounding bone. With further studies, PTH may potentially be used clinically to enhance tissue integration in these challenging environments.

Keywords Parathyroid hormone - Prostheses and implants · Canine $\cdot$ Biomechanics $\cdot$ Histomorphometry

\section{Introduction}

Long-term survival of uncemented total joint replacements relies on initial mechanical stability, early osseointegration, and peri-implant bone [1,2]. Implants are designed to have stability through exact- or press-fit insertion in cancellous bone. However, due to individual bone variation and rasping, gaps unavoidably occur along the length of the prosthesis at the time of insertion. Lasting secure fixation requires additional new bone formation, rapidly bridging the peri-implant gaps and new bone within the porosity of the implant surface, besides interfacial bone-implant attachment. Rapid bone growth protects the bone-implant interface against subsequent fluid pressure with wear-particle osteolysis and fibrous encapsulation.

Postoperative administration of parathyroid hormone (PTH) may potentially stimulate gap healing and increase early implant fixation. PTH has been shown to have an anabolic effect on bone when administered intermittently. The effect is an increase in osteoblast number and activity, 
leading to increases in cancellous bone mass and strength [3-9]. Fracture studies show that PTH augments fracture healing [10-14]. Some studies have investigated the effect of PTH on various types of implant fixation. These comprise rodent models with insertion in pathological bone [1518] or transcortical implantation in normal bone [19-27]. The general findings are improved bone incorporation. No studies are available about the effects of PTH treatment on peri-implant gap healing in normal cancellous bone.

In a parallel 4-week canine study we determined the effect of PTH on early fixation of titanium implants inserted press-fit without peri-implant bone defects in cancellous bone [28]. Systemic PTH(1-34) improved new bone formation but did not increase mechanical fixation. Given the clinical prevalence in joint replacement of gaps surrounding meticulously inserted press-fit implants, it is of interest to evaluate the effect of PTH on implant osseointegration in a more challenging environment where the implant is surrounded by a gap.

We test the hypothesis that PTH(1-34) increases early bone-implant contact (BIC), peri-implant bone volume, and mechanical fixation of implants inserted in a gap in normal cancellous bone.

\section{Materials and Methods}

\section{Study Design}

The experimental study was performed in 20 canines. A porous coated gap-implant device was inserted in the extra-articular metaphyseal cancellous bone of the right proximal tibia in a 1-mm gap (Fig. 1). Animals were randomized postoperatively to either systemic PTH or control, and the observation period was 4 weeks.

\section{Test Animal}

Our institution's Animal Care and Use Committee approved the study. Twenty male American hound dogs (HRP Covance Research Products, Kalamazoo, MI) were purpose-bred for research, skeletally mature (verified radiographically), with an age mean (range) of 13.8 (11.6-20.0) months and a weight mean (range) of 24.8 $(21.0-28.9) \mathrm{kg}$. Animals were housed individually but socialized in groups with 1-2 hours of daily exercise.

\section{Hormone Administration}

PTH and drug vehicle were prepared in a sterile environment using a vehicle of heat-inactivated $\left(56^{\circ} \mathrm{C}, 1 \mathrm{~h}\right) 2 \%$ canine serum (S-1757; Sigma-Aldrich, St. Louis, MO) in $0.9 \% \mathrm{NaCl}$ adjusted to $\mathrm{pH} 5$. The drugs for the whole study

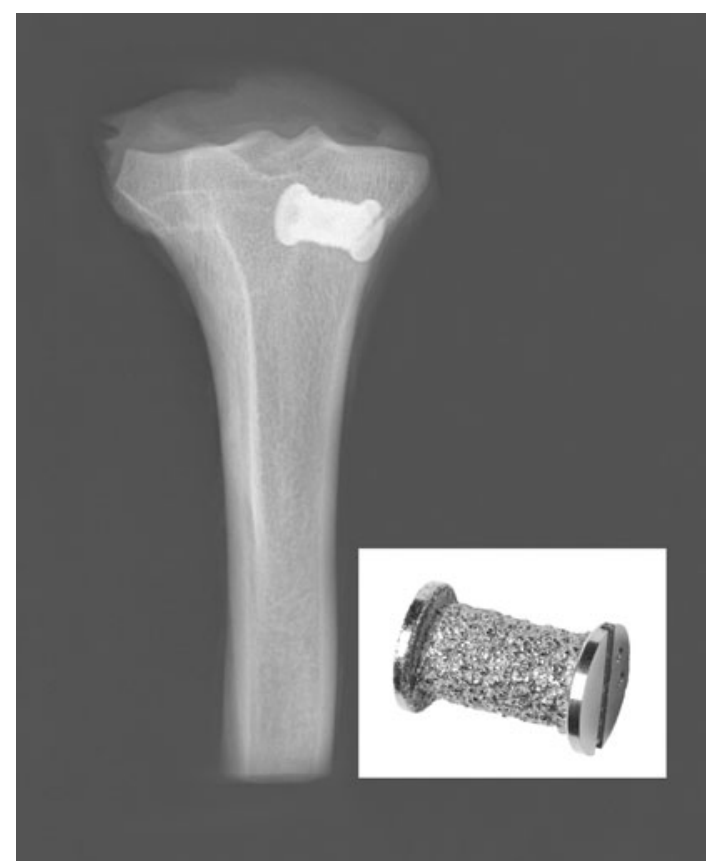

Fig. 1 Gap-implant device inserted in proximal tibia in a 1-mm gap. Implant diameter $6 \mathrm{~mm}$, length $10 \mathrm{~mm}$, end washer $8 \mathrm{~mm}$. Porous coat of plasmaspray titanium alloy $\left(\mathrm{Ti}_{6} \mathrm{Al}_{4} \mathrm{~V}\right)$

were prepared all at once and stored at $-20^{\circ} \mathrm{C}$. The intervention group was injected with human $\mathrm{PTH}(1-34)$ (research grade; Bachem Holding, Bubendorf, Switzerland) subcutaneously $5 \mu \mathrm{g} / \mathrm{kg}$ body weight adjusted to body weight weekly. Injections were daily (with the exception of one day) between 8:00 and 10:00 a.m. starting the day after surgery with postoperative randomization. On day 11 PTH(1-34) was changed from research grade to GMP grade (Bachem, Torrance, CA) with unaltered dosage due to concern over trifluoroacetic acid (TFA) content. The control group was injected with the equivalent volume of drug vehicle. Total serum calcium was collected twice in the observation period. Other unrelated studies on PTH treatment in other implant environments were conducted at other bone sites in this set of test animals.

Implants

Cylindrical, plasma-sprayed, porous coated titanium alloy implants $\left(\mathrm{Ti}_{6} \mathrm{Al}_{4} \mathrm{~V}\right.$ ELI, ASTM F136; Biomet, Warsaw, IN) were inserted in a 1-mm circumferential gap (Fig. 1). Implants were custom-made, cylindrical, with a porous coat surface of plasma-sprayed titanium alloy $\left(\mathrm{Ti}_{6} \mathrm{Al}_{4} \mathrm{~V}\right.$ ELI, ASTM F136) superimposed on an implant core of similar titanium composition. The coating process by the manufacturer is the same in both the manufacturer's clinical implant and the experimental implants. The coatings are considered equal. The nominal diameter was $6 \mathrm{~mm}$ (mean 
[SD] $6.2[0.06] \mathrm{mm}$ ) and the length was $10 \mathrm{~mm}$. An end-cap with a nominal diameter of $8 \mathrm{~mm}$ centralized the implant in the implant bed. Implants were cleaned in an ultrasonic bath of trichlorethylene with final baths of alcohol and then autoclave-sterilized. A surface topographic analysis was carried out on four randomly chosen implants (Somicronic Surfascan 3CS; Hommel Somicronic, Saint-André-de-Corcy, France) (Danish Technological Institute, Copenhagen, Denmark). The implant roughness was mean (range) Ra (arithmetic average of the deviation from the mean line over a sampling length) $=66.1(60.7-72.8) \mu \mathrm{m}, \mathrm{Rz}$ (average height difference between the five highest peaks and the five lowest valleys) $=307.1(290.4-323.3) \mu \mathrm{m}, \mathrm{Rq}$ (root mean square value of the profile departure $)=79.0(72.8-85.5) \mu \mathrm{m}$, and Rmax (maximum peak-to-valley height) $=307.1$ (290.4-323.3) $\mu \mathrm{m}$.

\section{Surgery}

Surgery was performed under sterile conditions and under general anesthesia. Premedication included atrophine 0.4 $\mathrm{mg} / \mathrm{ml} 1 \mathrm{ml} / 4.5 \mathrm{~kg}$ s.c. and acepromazine $10 \mathrm{mg} / \mathrm{ml} 0.1 \mathrm{ml} /$ $4.5 \mathrm{~kg}$ s.c. Anesthesia was covered by thiopental $5 \% 8 \mathrm{ml}$ i.v. prior to intubation and maintenance by inhalation isoflurane $1.5 \%$. Postoperative pain management consisted of wound infiltration with bupivacaine $2.5 \mathrm{mg} / \mathrm{ml} 2 \mathrm{ml}$ and intramuscular injections of bupronex (buprenorphine) $0.3 \mathrm{mg} / \mathrm{ml} 0.01 \mathrm{mg} / \mathrm{kg}$ daily for 3 days. Prophylactic antibiotic rocephone (ceftriaxone) was administered preoperatively $1 \mathrm{~g}$ i.v. and for the first 3 days $1 \mathrm{~g}$ i.v./day.

The anteromedial surface of the proximal tibia was exposed by a medial incision sparing the medial collateral ligament. The periosteum was elevated and a $2.5-\mathrm{mm}$ guidewire inserted into the proximal tibial metaphyseal bone $12 \mathrm{~mm}$ from the femoral-tibial joint line, perpendicular to the anterior medial bone surface. An 8.0-mm cannulated drill prepared the cylindrical bone cavity, with speed less than two revolutions per second and cooling with saline irrigation drip. Immediately after drilling, the implant was inserted and solid fixation was obtained. The overlying soft tissue was closed in layers. Postoperatively, the canines were allowed unrestricted weight bearing. $\mathrm{X}$-rays were obtained to confirm correct implant position. The same surgeon inserted all implants.

\section{Specimen Preparation}

Bacterial cultures were taken at removal of bones with implants in situ, and bone specimens were frozen at $-20^{\circ} \mathrm{C}$ until sectioning. Specimen preparation was done in a blinded fashion as to treatment group. Two transverse bone-implant specimens were obtained using a watercooled diamond band saw and implant-based alignment post (Exact Apperatebau, Nordstedt, Germany) (Fig. 2). The first and most superficial specimen with a thickness of $3.5 \mathrm{~mm}$ was used for mechanical testing and stored at $-20^{\circ} \mathrm{C}$. The inner $6.5-\mathrm{mm}$ implant section was fixed in alcohol $70 \%$ and prepared for undecalcified histomorphometric evaluation with implant in situ.

\section{Histological Analysis}

Specimens were dehydrated in graded ethanol (range 70-100\%) containing 0.4\% basic fuchsine (Merck, Darmstadt, Germany) followed by embedding in methylmethacrylate (MMA; Merck, Hohenbruun, Germany). The specimen bloc was randomly rotated around its long axis, and four vertical uniform random sections were cut with a hard tissue microtome (KDG-95; MeProTech, Heerhugoward, the Netherlands) [29]. These techniques have been shown to provide reliable results with minimal bias [30]. Sections were cut serially at the center part of the implant, parallel to the implant's long axis, and $400 \mu \mathrm{m}$ apart as the space minimally achieved due to the kerf of the saw. The thickness mean (SD) was $40.8(7.1) \mu \mathrm{m}$. The surface was counterstained with $2 \%$ light green (Light Green SF; BDH Laboratory Supplies, Poole, UK) for 2 min [31]. The staining technique distinguishes bone at the specimen surface (green) and fibrous tissue/marrow-like tissue (red). The penetration depth of the light green stain has been determined to be in the range of 4-10 $\mu \mathrm{m}$ [32], enabling determination of the superficial morphological focus plane for histomorphometric tissue sampling.

Static histomorphometry quantified tissue ongrowth at the implant surface (percentage coverage of implant surface) and peri-implant tissue volume (volume percentage). Analysis was performed blinded in random specimen order with a light microscope (Olympus BX51 TF; Olympus Optical, Tokyo, Japan) and a computer-assisted stereologic image analysis system (Cast, version 2.1.4; Olympus, Albertslund, Denmark).

Regions of the $1 \mathrm{~mm}$ gap were defined along the whole section as an outer gap region of $500 \mu \mathrm{m}$, an inner gap region reaching the implant, and a $1,000-\mu \mathrm{m}$ circumferential region of the host bone not subjected to implantation (Fig. 3). Tissue ongrowth was defined as tissue directly at the implant surface and estimated by the line intercept technique with randomly disposed sine-weighted lines. Peri-implant tissue volume was estimated using point counting with randomly disposed points. The test system was calibrated with a minimum of 100 line interceptions and points for the tissue of interest in each region. Sampling was done by the meander method. Each zone was evaluated separately during a specimen sampling session. The specimen preparation, stereologic software, and systematic uniform random sampling made it possible to obtain unbiased 
Fig. 2 Sectioning technique. Implant in situ tibial metaphyseal bone. Outer Section $3.5 \mathrm{~mm}$ for mechanical testing, inner Section $6.5 \mathrm{~mm}$ for histomorphometry
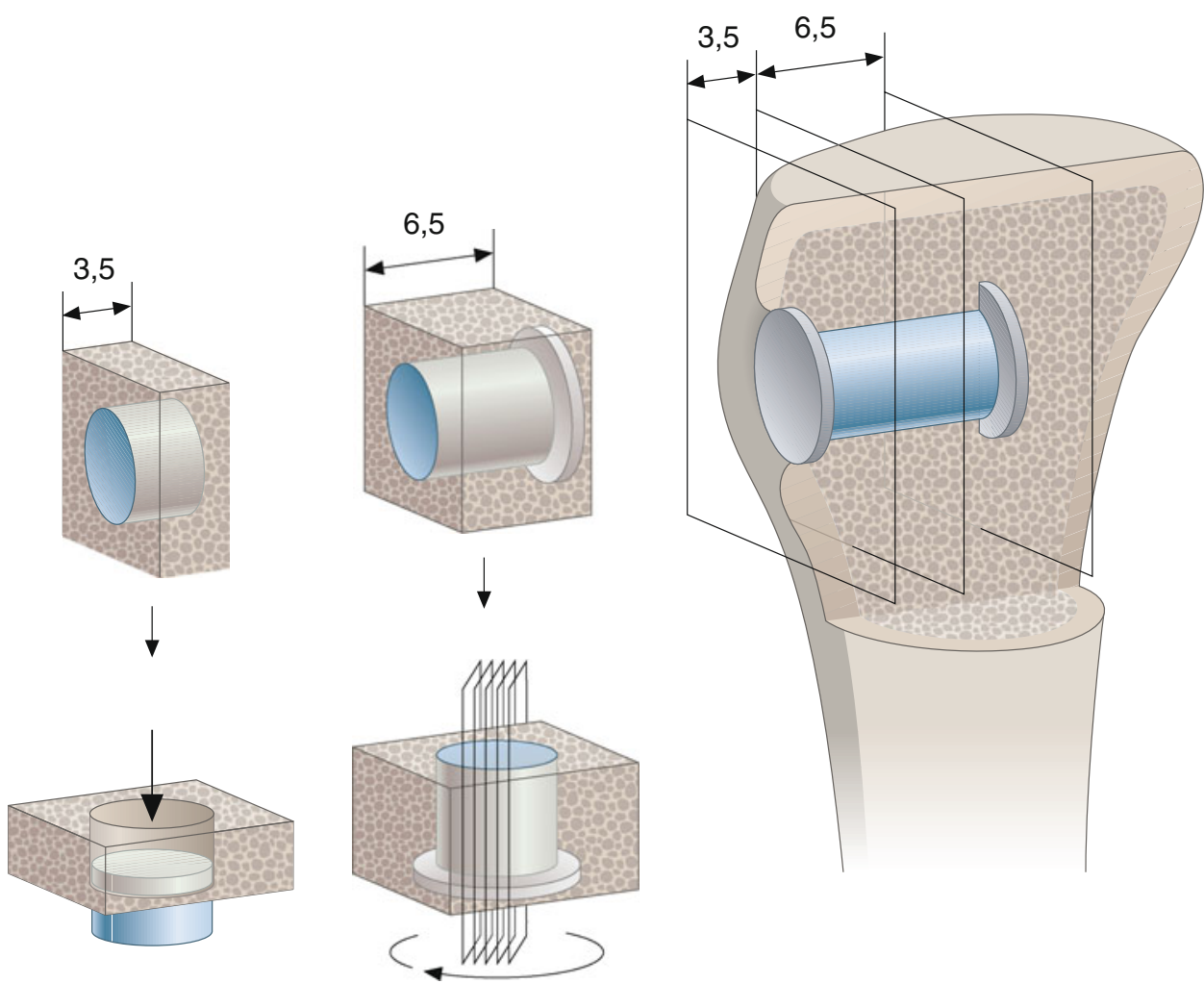

estimates, although anisotropy of cancellous bone exists [29, 33]. All implant-related measurements were done by the same person (primary author H. D.). For comparisons of intact bone, measurements were completed by an experienced histomorphometry technician (J. P.). Reproducibility was defined by determination in duplicate by the same person (H. D.) of two PTH and two control implants (16 specimens) randomly selected. The coefficients of variation for bone were 2 and $6 \%$ in the outer/inner gap regions and $7 \%$ at the implant interface.

\section{Mechanical Testing}

Implants were tested to failure by axial push-out test (MTS 858 Mini Bionix, Software MTS Test Star 790.00, version 4.00; MTS System, Minneapolis, MN). Testing was done blinded and all in one session. Push-out was done from the external side of the bone inward. Specimens were placed on a metal support jig with a 7.4-mm-diameter circular central opening, leaving a $0.7-\mathrm{mm}$ distance between the implant and support jig as recommended by Dhert et al. [34]. A preload of $2 \mathrm{~N}$ defined the standardized contact position for starting the test. A standard displacement velocity of $5 \mathrm{~mm} /$ minute was used. Continuous load-displacement data were recorded, obtaining maximum shear stiffness (slope of the linear section of the load vs. displacement curve), ultimate shear strength (maximum force applied until failure of the bone-implant interface), and total energy absorption (area under the load-displacement curve until failure). All pushout parameters were normalized by the cylindrical surface area of the implant. Determining the reproducibility of the push-out test was not possible due to its destructive nature.

Statistical Analysis

STATA statistical software (Stata 10.1; StataCorp, College Station, TX) was used. Because data were not normally distributed, statistical analysis was the nonparametric twosample Wilcoxon rank-sum (Mann-Whitney) test with assessment of the difference between treatment groups. Estimates are given as medians and interquartile ranges, and two-tailed $P$ values $<0.05$ are considered statistically significant. The sample size was based on a sample size estimation, which was carried out prior to the study based on previous studies at our institution in this implant model.

\section{Results}

\section{Surgery}

The day after surgery all animals were fully weight-bearing. Two animals in the PTH group died on days 6 and 8 postoperatively. Autopsy revealed ventricular hypertrophy and myositis in both. All other animals completed the observation period with no abnormal serum calcium levels. 


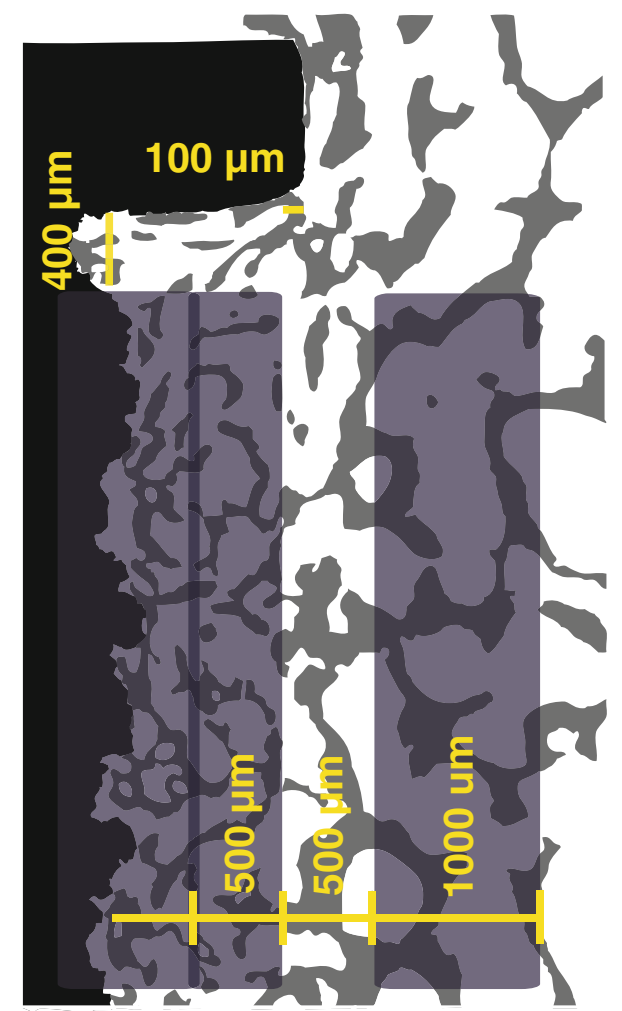

Fig. 3 Histomorphometry. Region of interest (ROI) is on both implant sides and illustrated on one side above. Tissue ongrowth at interface. Tissue volume in gap of $1 \mathrm{~mm}$ divided in two of an in inner gap region and an outer gap region $(500 \mu \mathrm{m})$. Tissue volume in region of intact nonimplanted bone $(1,000 \mu \mathrm{m})$. Regions defined from washer margins as a fixed point with a $100-\mu$ m clearance at gap-intact bone interface and $400 \mu \mathrm{m}$ below washer. ROI definition objective/ total magnification $\times 1.25 / \times 54$, data sample at $\times 10 / \times 431$

No other complications and no signs of infection in the implant sites were observed. All bacterial cultures taken at the time of death were negative.

\section{Histology}

A qualitative histological examination revealed that bone in the gap in the PTH group consisted of abundant immature bone with no specific orientation of trabeculae forming a fine-meshed bone web (Fig. 4). Trabeculae were thicker and more numerous and had improved connectivity compared to the control group. In PTH specimens trabeculae were more abundant but appeared thinner in the gap region compared to the region of intact host bone. Fibrous tissue was observed in six PTH implants and five controls and located at the bone-implant interface.

\section{Histomorphometry}

PTH caused a significant increase in new bone in the 1-mm peri-implant gap (Table 1). In the outer half of the gap a 2.5-fold median increase was seen, and similarly a 2.4-fold increase was seen in the inner part. At the interface, PTH increased bone contact nonsignificantly by a median of 1.6-fold $(P=0.07)$. Fibrous tissue was only observed in the inner gap, and no significant differences were seen in the gap or at the interface between the PTH and control groups. No differences in bone or fibrous tissue were observed in the $1,000-\mu \mathrm{m}$ remaining peri-implant region of the host bone not subjected to implantation.

\section{Mechanical Testing}

Results of the mechanical testing are summarized in Fig. 5. One mechanical implant specimen was excluded during mechanical testing due to oblique placement on the support jig. Randomization code post hoc revealed the implant to be in the control group. PTH significantly increased shear stiffness 2-fold, with a median (interquartile range) of PTH 17.4 (12.7-39.7) $\mathrm{MPa} / \mathrm{mm}$ and control 8.8 (3.3-12.4) $\mathrm{MPa} / \mathrm{mm}$. Energy absorption was significantly 1.7 -fold higher, with a median (interquartile range) of PTH 781 $(595-1,198) \mathrm{J} / \mathrm{m}^{2}$ and control $470(189-596) \mathrm{J} / \mathrm{m}^{2}$. Shear strength demonstrated a nonsignificant 1.5 -fold increase with PTH 3.0 (2.6-4.9) MPa and control 2.0 (0.9-3.0) MPa $(P=0.08)$.

\section{Discussion}

The purpose of this study was to determine whether intermittent systemic PTH(1-34) had an effect on the early fixation of implants inserted in a gap in cancellous bone. We found a significant increase in bone volume in both the inner and outer parts of the 1-mm gap. Increased bone contact with the implant surface was observed but was not significant. No bone volume enhancement was seen in the region of intact nonimplanted bone surrounding the implant. PTH increased significantly the mechanical implant fixation in shear stiffness and energy absorption.

We used an established experimental model designed to represent a cementless human joint replacement prosthesis surrounded by cancellous bone. The implant was inserted in a well-defined gap of normal nonpathological bone and was porous coated with the same technique as for the clinical applications of the manufacturer's prostheses. The model was nonarticular and not directly weight bearing, which partly omits the effect of the mechanical stimuli on bone formation alone or as a PTH enhancement [35]. Based on previous implant studies, the gap size of $1 \mathrm{~mm}$ is sufficient to delay or prevent substantial healing without intervention during a 4-week observation period [36]. Also, abundant cancellous bone in this test animal limits interference of a cortical envelope in contributing to implant 
Fig. 4 Histology.

Photomicrographs of representative histological samples. a, b Control sample. c, d PTH sample.

a, c Magnification $\times 45$, bar $=1,000 \mu \mathrm{m}$.

b, d Magnification $\times 160$, bar $=500 \mu \mathrm{m}$. Staining technique $0.4 \%$ basic fuchsin (red) and 2\% light green $($ green $=$ bone $)$. PTH shows increase in bone in the gap with no specific orientation of trabeculae. The intact bone outside the gap is visible (Color figure online)
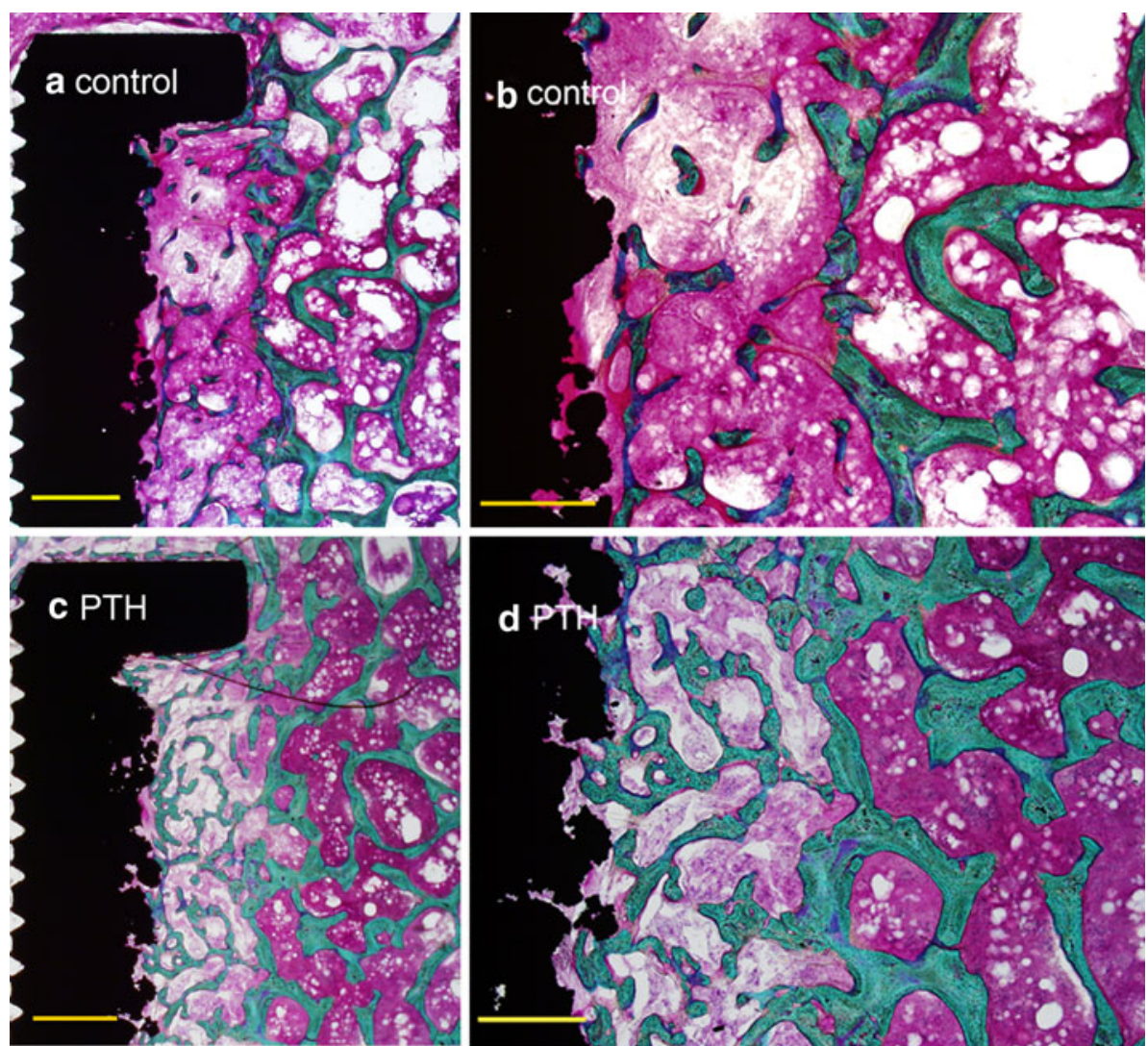

Table 1 Histomorphometry

\begin{tabular}{llll}
\hline & Bone & Marrow & Fibrous \\
\hline $\begin{array}{lll}\text { Interface } \\
\text { Control }\end{array}$ & $10(7-12)$ & $77(70-88)$ & $8(0-21)$ \\
PTH & $16(11-20)^{1)}$ & $74(56-80)$ & $7(0-35)$ \\
Inner gap & & & \\
Control & $13(11-18)$ & $82(77-85)$ & $2(0-7)$ \\
PTH & $33(26-36)^{* * *}$ & $60(53-69)^{* *}$ & $3(0-14)$ \\
Outer gap & & & \\
Control & $10(6-14)$ & $90(86-94)$ & $0(0-0)$ \\
PTH & $27(20-37)^{* *}$ & $73(63-80)^{* *}$ & $0(0-0)$ \\
Intact bone & & & $0(0-0)$ \\
Control & $22(19-23)$ & $78(77-81)$ & $0(0-0)$ \\
PTH & $22(18-30)$ & $78(70-82)$ & \\
\hline
\end{tabular}

Implant inserted in concentric gap $1 \mathrm{~mm}$ in cancellous bone. PTH treatment versus control. Bone, marrow-like and fibrous tissue at implant surface (surface fraction), concentric region divided in two of inner gap, outer gap $(500 \mu \mathrm{m})$, and intact bone outside the gap $(1,000 \mu \mathrm{m})$ (volume fraction). PTH $n=8$, control $n=10$. MannWhitney test, median, interquartile range, $* * P<0.01$, *** $P<$ $0.001,{ }^{1)} P=0.07$, PTH compared to control within region

integration. The single sex of animals (male) reduces interindividual biological variation in bone structure. When initiating new treatments for human joint replacements, it is crucial that evaluation is done in clinically relevant animal and bone models. It is known that the magnitude of bone anabolic response to intermittent PTH depends on species, bone sites, and bone envelopes [6, 7, 37-39]. PTH has not previously been evaluated in this canine model. The canine bone structure most closely resembles human bone and the sites for implantation [40-42]. The native PTH(1-84) and PTH(1-34) fragments show equivalent biological activities at equimolar concentrations [43]. However, the bone anabolic window of PTH is both doseand time-dependent $[10,13,19]$. We chose a single dose of PTH(1-34) $5 \mu \mathrm{g} / \mathrm{kg}$ body weight with dosage within the range studied with other animal models and relevant as to this animal species $[3,7,44-46]$. The systemic nature of PTH administration required an unpaired study design. A low concentration of TFA is present in research-grade PTH. After two test animals died, as a precaution we changed PTH to GMP grade from day 11 with the same dosage (Bachem Certificate of Analysis). For the remaining observation period the animals were closely monitored, and all completed the course uneventfully.

The osseointegration of an implant may be considered as a cancellous bone healing process bridging peri-implant gaps. With a titanium alloy implant being bioinert, conventional gap healing is by unidirectional intramembranous ossification encircling the implant [36]. With intermittent 


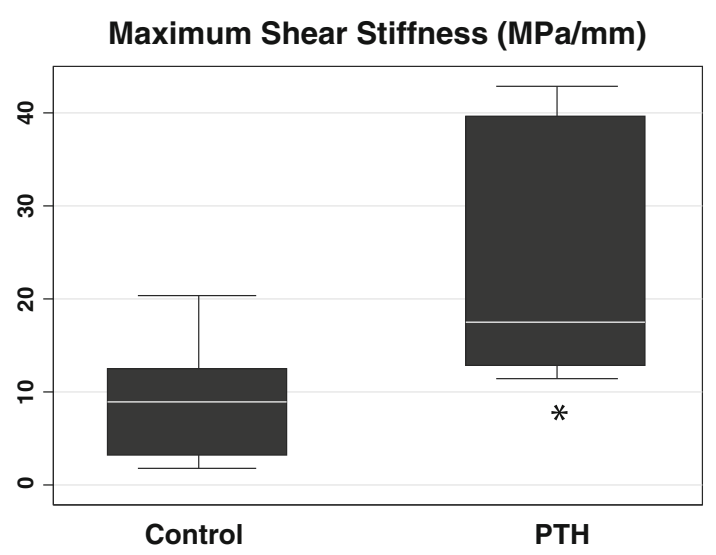

Maximum Shear Strength (MPa)

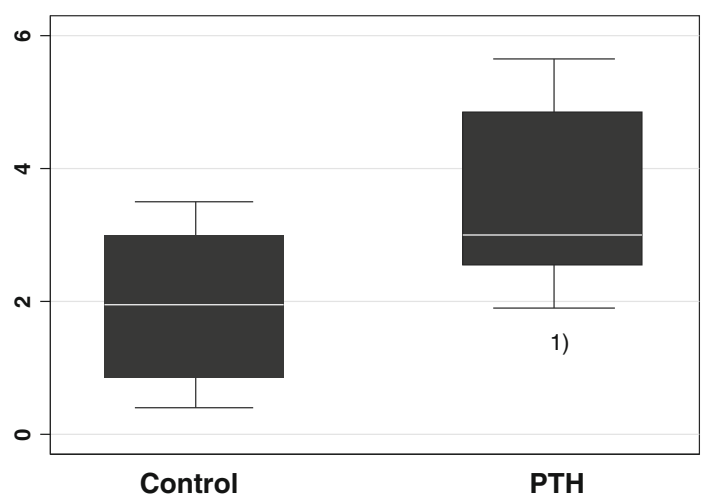

Total Energy Absorption (J/m2)

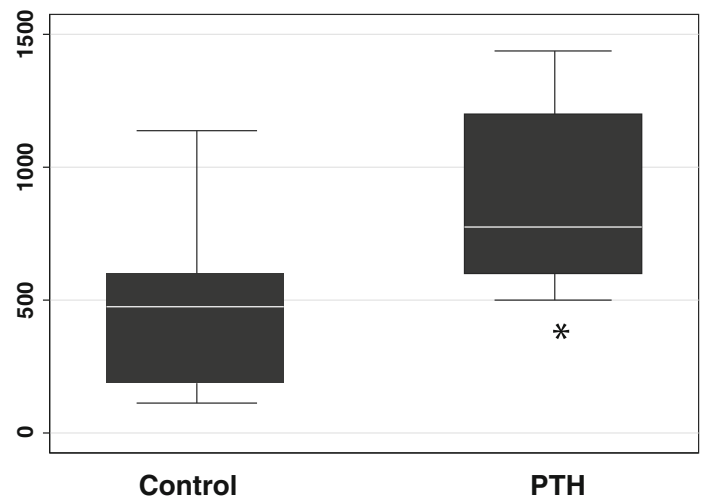

Fig. 5 Mechanical testing push-out-to-failure. Box plot, median, quartiles, sample range. Maximum shear stiffness, maximum shear strength, and total energy absorption. Control $n=9$, PTH $n=8$. Mann-Whitney test $* P<0.05,{ }^{1)} P=0.08$, PTH compared to control

PTH treatment, the fundamental anabolic mechanism is more complex. The PTH-enhanced regenerative process in fracture healing may differ from the gap healing of a bonematerial interface. PTH increases osteoblast number and activity [47] by recruiting osteoprogenitor cells [6] and transforming resting bone lining cells $[5,6]$. PTH also stimulates chondrogenesis by recruitment of chondroprogenitor cells [48]. Bone formation of $\mathrm{PTH}(1-34)$ has been evaluated by placing bone conduction chambers in endosteal bone of rat tibia [49] and rabbit mandible [50]. Skripitz et al. [49] found from weeks 2 to 6 a small and nonsignificant increase in ingrowth distances of bone into the chamber, a metaplastic (membranous) ossification, and with time a fivefold increase in bone density within the bone chamber. In nonimplanted remodeling bone in the same rats an increase in density was barely detectable. In our study new bone had already extended homogenously into the entire gap in the PTH group and no significant differences were seen in bone volume between the inner and outer gap regions. Given the 4-week observation period in a 1-mm gap, discrimination is not possible between an ossification process of an osteoconductive ossification frontline progressively expanding unidirectionally or a contribution of osteoinductive ossification inlets scattered in the gap expanding multidirectionally. PTH may show potency in initial healing of even larger peri-implant defects.

The data indicate that PTH could be used clinically. We found PTH treatment to increase peri-implant gap bone volume $(P<0.01)$. The BIC increase was not significant $(P=0.07)$, while there was an unaltered amount of bone in the surrounding intact bone region. The mechanical resistance of an implant relies on the amount of bone adjacent to the implant, its quality, and its trabecular architecture. PTH increased early mechanical fixation in shear stiffness and energy absorption. The increase in shear strength was nonsignificant $(P=0.08)$ and may be subscribed to BIC with the near-significant improvement in bone interlocking statically to the implant surface. Also, the time interval observed, the level of bone maturation, and the loss of a test animal in the PTH group may be taken into consideration. With respect to the influence of PTH on bone regeneration, Andreassen et al. [10] reported that in normal adult rats 60 and $200 \mu \mathrm{g} / \mathrm{kg}$ daily PTH(1-34) increased the amount of callus and mechanical strength of fractures after 40 days of healing. Proportionate findings are documented in other studies with PTH(1-34) and PTH(1-84) in rats [11, 12, 51], larger animals [13], and recently in humans [14]. No previous study has determined the effect of gap healing with PTH(1-34) on implants inserted in a defined bone defect with normal cancelleous bone of human characteristics. Instead, fixation of prostheses by adjuvant PTH administration has so far been confined to rodents in situations of screws implanted transcortically with part of the screw being in cortical bone [18-21, 23, 24, 26, 27] or of rods in bone with pathological low bone density [15-17, 52]. The general findings in these interference fit rodent models are improved incorporation in bone. In ovariectomized rats, administering PTH(1-34) 5, 25, or $75 \mu \mathrm{g} / \mathrm{kg}$ daily for 8 weeks increased mechanical pull-out force, stiffness, and toughness of conical titanium screws. Osseointegration and 
bone volume were increased with no difference between the highest doses [15]. PTH(1-34), $25 \mu \mathrm{g} / \mathrm{kg}$ five times weekly, rescued the peri-implant bone volume and mechanical function by augmenting trabecular thickness [23]. PTH(1-34), $60 \mu \mathrm{g} / \mathrm{kg}$ three times a week, increased the pull-out strength of screws implanted transcortically in normal bone of rats at 2 and 4 weeks and implant bone contact at 1,2, and 4 weeks [21]. We determined in a parallel 4-week canine study that systemic PTH(1-34) $5 \mathrm{ug} / \mathrm{kg}$ daily does not improve the early implant fixation of porous coated titanium alloy implants inserted press-fit [28]. Stimulating new bone formation at the bone-implant interface did not improve the overall mechanical resistance to push-out. Using a test-animal model of clinical relevance with comparable bone quality and implanted cancellous bone envelope, press-fit implants showed moderate improvement with PTH. In the present study inserting implants in a situation of peri-implant bone defects initiates a regenerative process of bone repair in the gap, which is significantly improved by PTH.

\section{Conclusion}

Intermittent treatment with PTH enhances early fixation of orthopedic implants surrounded by a gap in terms of increased bone in the gap and increased mechanical stability. Treatment with PTH exerts its bone-stimulatory effect locally around the implant when administered for a short period, with no observed general bone effect. These findings suggest that in joint replacements adjuvant PTH may be useful in improving healing of the inevitable periimplant bone defects. Further studies are needed with respect to the short-term effects of $\mathrm{PTH}$, on time and dose dependence, in critical gap size, and other implant settings, as well as long-term changes in bone in the gap after cessation of PTH administration.

Acknowledgement This work was supported by the Einar Hansen Foundation, Erik Horslev Foundation, Korning Foundation, Velux Foundation, and the U.S. National Institutes of Health (AR42051). We thank the histomorphometric technicians Jane Pauli and Anette Milton.

Open Access This article is distributed under the terms of the Creative Commons Attribution Noncommercial License which permits any noncommercial use, distribution, and reproduction in any medium, provided the original author(s) and source are credited.

\section{References}

1. Engh CA, O'Connor D, Jasty M, McGovern TF, Bobyn JD, Harris WH (1992) Quantification of implant micromotion, strain shielding, and bone resorption with porous-coated anatomic medullary locking femoral prostheses. Clin Orthop Relat Res 285:13-29

2. Karrholm J, Borssen B, Lowenhielm G, Snorrason F (1994) Does early micromotion of femoral stem prostheses matter? 4-7-year stereoradiographic follow-up of 84 cemented prostheses. J Bone Joint Surg Br 76:912-917

3. Inoue J, Takahashi H, Konno T (1985) Histomorphometric evaluation on ilium of beagle dogs with long-term administration of low-dose 1-34 PTH. Bone 6:401-402

4. Li M, Liang H, Shen Y, Wronski TJ (1999) Parathyroid hormone stimulates cancellous bone formation at skeletal sites regardless of marrow composition in ovariectomized rats. Bone 24:95-100

5. Dobnig H, Turner RT (1995) Evidence that intermittent treatment with parathyroid hormone increases bone formation in adult rats by activation of bone lining cells. Endocrinology 136:36323638

6. Nishida S, Yamaguchi A, Tanizawa T, Endo N, Mashiba T, Uchiyama Y, Suda T, Yoshiki S, Takahashi HE (1994) Increased bone formation by intermittent parathyroid hormone administration is due to the stimulation of proliferation and differentiation of osteoprogenitor cells in bone marrow. Bone 15:717-723

7. Jerome CP, Burr DB, Van BT, Hock JM, Brommage R (2001) Treatment with human parathyroid hormone (1-34) for 18 months increases cancellous bone volume and improves trabecular architecture in ovariectomized cynomolgus monkeys (Macaca fascicularis). Bone 28:150-159

8. Oxlund H, Dalstra M, Ejersted C, Andreassen TT (2002) Parathyroid hormone induces formation of new cancellous bone with substantial mechanical strength at a site where it had disappeared in old rats. Eur J Endocrinol 146:431-438

9. Zhang L, Takahashi HE, Tanizawa T, Endo N, Yamamoto N, Hori M (1998) Low dose of human PTH(1-34) improved tibial subcortical bone mass without further cortical bone loss in adult intact beagles. J Bone Miner Metab 16:96-99

10. Andreassen TT, Ejersted C, Oxlund H (1999) Intermittent parathyroid hormone (1-34) treatment increases callus formation and mechanical strength of healing rat fractures. J Bone Miner Res 14:960-968

11. Nozaka K, Miyakoshi N, Kasukawa Y, Maekawa S, Noguchi H, Shimada Y (2008) Intermittent administration of human parathyroid hormone enhances bone formation and union at the site of cancellous bone osteotomy in normal and ovariectomized rats. Bone 42:90-97

12. Alkhiary YM, Gerstenfeld LC, Krall E, Westmore M, Sato M, Mitlak BH, Einhorn TA (2005) Enhancement of experimental fracture-healing by systemic administration of recombinant human parathyroid hormone (PTH 1-34). J Bone Joint Surg Am $87: 731-741$

13. Manabe T, Mori S, Mashiba T, Kaji Y, Iwata K, Komatsubara S, Seki A, Sun YX, Yamamoto T (2007) Human parathyroid hormone (1-34) accelerates natural fracture healing process in the femoral osteotomy model of cynomolgus monkeys. Bone 40:1475-1482

14. Aspenberg P, Genant HK, Johansson T, Nino AJ, See K, Krohn K, Garcia-Hernandez PA, Recknor CP, Einhorn TA, Dalsky GP, Mitlak BH, Fierlinger A, Lakshmanan MC (2009) Teriparatide for acceleration of fracture repair in humans: a prospective, randomized, double-blind study of 102 postmenopausal women with distal radial fractures. J Bone Miner Res 25:404-414

15. Gabet Y, Muller R, Levy J, Dimarchi R, Chorev M, Bab I, Kohavi D (2006) Parathyroid hormone 1-34 enhances titanium implant anchorage in low-density trabecular bone: a correlative micro-computed tomographic and biomechanical analysis. Bone 39:276-282

16. Shirota T, Tashiro M, Ohno K, Yamaguchi A (2003) Effect of intermittent parathyroid hormone (1-34) treatment on the bone 
response after placement of titanium implants into the tibia of ovariectomized rats. J Oral Maxillofac Surg 61:471-480

17. Ohkawa Y, Tokunaga K, Endo N (2008) Intermittent administration of human parathyroid hormone (1-34) increases new bone formation on the interface of hydroxyapatite-coated titanium rods implanted into ovariectomized rat femora. J Orthop Sci 13:533542

18. Skripitz R, Johansson HR, Ulrich SD, Werner A, Aspenberg P (2009) Effect of alendronate and intermittent parathyroid hormone on implant fixation in ovariectomized rats. J Orthop Sci 14:138-143

19. Skripitz R, Andreassen TT, Aspenberg P (2000) Strong effect of PTH (1-34) on regenerating bone: a time sequence study in rats. Acta Orthop Scand 71:619-624

20. Skripitz R, Aspenberg P (2001) Implant fixation enhanced by intermittent treatment with parathyroid hormone. J Bone Joint Surg Br 83:437-440

21. Skripitz R, Aspenberg P (2001) Early effect of parathyroid hormone (1-34) on implant fixation. Clin Orthop Relat Res 392:427-432

22. Skripitz R, Bohling S, Ruther W, Aspenberg P (2005) Stimulation of implant fixation by parathyroid hormone (1-34) - a histomorphometric comparison of PMMA cement and stainless steel. J Orthop Res 23:1266-1270

23. Gabet Y, Kohavi D, Voide R, Mueller TL, Muller R, Bab I (2009) Endosseous implant anchorage is critically dependent on mechanostructural determinants of peri-implant bone trabeculae. J Bone Miner Res 25:575-583

24. Corsini MS, Faraco FN, Castro AA, Onuma T, Sendyk WR, Shibli JA (2008) Effect of systemic intermittent administration of human parathyroid hormone (rhPTH[1-34]) on the resistance to reverse torque in rabbit tibiae. J Oral Implantol 34:298-302

25. Aspenberg P, Wermelin K, Tengwall P, Fahlgren A (2008) Additive effects of PTH and bisphosphonates on the bone healing response to metaphyseal implants in rats. Acta Orthop 79:111-115

26. Mair B, Tangl S, Feierfeil J, Skiba D, Watzek G, Gruber R (2009) Age-related efficacy of parathyroid hormone on osseointegration in the rat. Clin Oral Implants Res 20:400-405

27. Johansson HR, Skripitz R, Aspenberg P (2008) Bisphosphonates can block the deterioration in implant fixation after withdrawal of intermittent doses of parathyroid hormone. J Bone Joint Surg Br 90:400-404

28. Daugaard H, Elmengaard B, Lamberg A, Bechtold JE, Soballe K (2009) Osseointegration of implants inserted pressfit with parathyroid hormone as adjuvant therapy. In: European Federation of National Associations of Orthopaedics and Traumatology, 10th conference EFORT, June 3-6, Vienna, Austria

29. Overgaard S, Soballe K, Jorgen H, Gundersen G (2000) Efficiency of systematic sampling in histomorphometric bone research illustrated by hydroxyapatite-coated implants: optimizing the stereological vertical-section design. J Orthop Res $18: 313-321$

30. Baas J (2008) Adjuvant therapies of bone graft around noncemented experimental orthopedic implants stereological methods and experiments in dogs. Acta Orthop Suppl 79:1-43

31. Gotfredsen K, Budtz-Jorgensen E, Jensen LN (1989) A method for preparing and staining histological sections containing titanium implants for light microscopy. Stain Technol 64:121-127

32. Daugaard H, Elmengaard E, Andreassen T, Bechtold J, Soballe K (2009) Osseointegration of implants inserted pressfit with parathyroid hormone as adjuvant therapy. 10th European Federation of National Associations of Orthopaedics and Traumatology EFORT 2009

33. Gundersen HJ, Jensen EB (1987) The efficiency of systematic sampling in stereology and its prediction. J Microsc 147:229-263
34. Dhert WJ, Verheyen CC, Braak LH, de Wijn JR, Klein CP, de Groot K, Rozing PM (1992) A finite element analysis of the pushout test: influence of test conditions. J Biomed Mater Res 26:119-130

35. Sugiyama T, Saxon LK, Zaman G, Moustafa A, Sunters A, Price JS, Lanyon LE (2008) Mechanical loading enhances the anabolic effects of intermittent parathyroid hormone (1-34) on trabecular and cortical bone in mice. Bone 43:238-248

36. Soballe K (1993) Hydroxyapatite ceramic coating for bone implant fixation. Mechanical and histological studies in dogs. Acta Orthop Scand Suppl 255:1-58

37. Tashjian AH, Chabner BA (2002) Commentary on clinical safety of recombinant human parathyroid hormone 1-34 in the treatment of osteoporosis in men and postmenopausal women. J Bone Miner Res 17:1151-1161

38. Sietsema WK (1995) Animal models of cortical porosity. Bone 17:297S-305S

39. Brommage R, Hotchkiss CE, Lees CJ, Stancill MW, Hock JM, Jerome CP (1999) Daily treatment with human recombinant parathyroid hormone-(1-34), LY333334, for 1 year increases bone mass in ovariectomized monkeys. J Clin Endocrinol Metab 84:3757-3763

40. Eitel F, Klapp F, Jacobson W, Schweiberer L (1981) Bone regeneration in animals and in man. A contribution to understanding the relative value of animal experiments to human pathophysiology. Arch Orthop Trauma Surg 99:59-64

41. Aerssens J, Boonen S, Lowet G, Dequeker J (1998) Interspecies differences in bone composition, density, and quality: potential implications for in vivo bone research. Endocrinology 139:663670

42. Reeve J (1996) PTH: a future role in the management of osteoporosis? J Bone Miner Res 11:440-445

43. Oxlund $\mathrm{H}$, Ejersted $\mathrm{C}$, Andreassen TT, Torring $\mathrm{O}$, Nilsson $\mathrm{MH}$ (1993) Parathyroid hormone (1-34) and (1-84) stimulate cortical bone formation both from periosteum and endosteum. Calcif Tissue Int 53:394-399

44. Boyce RW, Paddock CL, Franks AF, Jankowsky ML, Eriksen EF (1996) Effects of intermittent hPTH(1-34) alone and in combination with $1,25(\mathrm{OH}) 2 \mathrm{D} 3$ or risedronate on endosteal bone remodeling in canine cancellous and cortical bone. J Bone Miner Res 11:600-613

45. Ma YF, Chen YY, Ijiri K et al (1997) PTH in combination with risedronate in aged beagle dogs resulted in bone balance similar to PTH alone. Bone 20:99

46. Zhang L, Takahashi HE, Inoue J, Tanizawa T, Endo N, Yamamoto N, Hori M (1997) Effects of intermittent administration of low dose human PTH(1-34) on cancellous and cortical bone of lumbar vertebral bodies in adult beagles. Bone 21:501-506

47. Pettway GJ, Meganck JA, Koh AJ, Keller ET, Goldstein SA, McCauley LK (2008) Parathyroid hormone mediates bone growth through the regulation of osteoblast proliferation and differentiation. Bone 42:806-818

48. Nakazawa T, Nakajima A, Shiomi K, Moriya H, Einhorn TA, Yamazaki M (2005) Effects of low-dose, intermittent treatment with recombinant human parathyroid hormone (1-34) on chondrogenesis in a model of experimental fracture healing. Bone 37:711-719

49. Skripitz R, Andreassen TT, Aspenberg P (2000) Parathyroid hormone (1-34) increases the density of rat cancellous bone in a bone chamber. A dose-response study. J Bone Joint Surg Br 82:138-141

50. Jung RE, Hammerle CH, Kokovic V, Weber FE (2007) Bone regeneration using a synthetic matrix containing a parathyroid hormone peptide combined with a grafting material. Int $\mathrm{J}$ Oral Maxillofac Implants 22:258-266 
51. Andreassen TT, Willick GE, Morley P, Whitfield JF (2004) Treatment with parathyroid hormone hPTH(1-34), hPTH(1-31), and monocyclic hPTH(1-31) enhances fracture strength and callus amount after withdrawal fracture strength and callus mechanical quality continue to increase. Calcif Tissue Int 74:351-356
52. Dayer R, Badoud I, Rizzoli R, Ammann P (2007) Defective implant osseointegration under protein undernutrition: prevention by PTH or pamidronate. J Bone Miner Res 22:1526-1533 